\title{
Surgical treatment of congenital anomalies of the aortic arch : Long-term results
}

\author{
Fabio Cuttone ${ }^{1 *}$, Romain Amadieu², Géraldine Labouret ${ }^{3}$, Lionel Berthomieu ${ }^{4}$, Sophie Breinig ${ }^{4}$, Sebastien Hascoet ${ }^{2}$, \\ Khaled Hadeed ${ }^{2}$, Daniel Roux', Yves Dulac ${ }^{2}$, Philippe Acar ${ }^{2}$, Bertrand Leobon ${ }^{1}$ \\ From World Society of Cardiothoracic Surgeons 25th Anniversary Congress, Edinburgh \\ Edinburgh, UK. 19-22 September 2015
}

\section{Background/Introduction}

Congenital anomalies of the aortic arch gather a wide spectrum of malformations concerning the aortic arch or some of its branches and the pulmonary artery. These malformations are rare (1 in 1000 live births) and sometimes responsible of complete (vascular ring) or partial (vascular sling) encirclement of the oesophagus, trachea or bronchi. In cases of symptomatic airways obstruction or oesophagus compression the surgical treatment is mandatory and curative.

In this paper we describe the experience of Children's Hospital of Toulouse on the surgical treatment of congenital anomalies of aortic arch.

\section{Aims/Objectives}

To evaluate the results and the clinical outcome of reconstructive surgery in patients affected by symptomatic vascular ring.

\section{Method}

Observational retrospective monocentric study including all the patients with a congenital anomaly of the aortic arch submitted to surgical treatment since May 2010, at the Children's Hospital of Toulouse.

\section{Results}

Between May 2010 and March 2015, 10 patients (3 girls and 8 boys) underwent surgical treatment for vascular ring responsible for a tracheo-esophageal compression: 9 double aortic arch including 7 right dominant arches, 1 left dominant, 1 balanced disposition and 1 child with a Neuhauser anomaly.

${ }^{1}$ Department of Cardiac Surgery, University Hospital (CHU), Toulouse, France Full list of author information is available at the end of the article
The average age and weight were respectively $2.5 \pm$ 1.5 years and $12.9 \pm 3.7 \mathrm{~kg}$. Surgical correction was carried out mainly by postero-lateral thoracotomy and was performed without complication. The mean duration of mechanical ventilation was $6 \pm 7$ hours and the average length of stay in intensive care was $1.7 \pm 0.7$ days. The average hospital stay was $4.8 \pm 1.2$ days. All patients are alive at the time of the last follow-up and asymptomatic with normal growth.

\section{Discussion/Conclusion}

In this series, the surgical treatment of aortic arch anomalies was curative in all cases without associated morbidity and with good functional midterm results. The diagnosis is often delayed and more frequently suspected on the basis of respiratory symptoms.

\section{Consent}

Written informed consent was obtained from the patient for publication of this abstract and any accompanying images. A copy of the written consent is available for review by the Editor of this journal.

\section{Authors' details \\ ${ }^{1}$ Department of Cardiac Surgery, University Hospital (CHU), Toulouse, France. ${ }^{2}$ Department of Cardiology, University Hospital (CHU), Toulouse, France. \\ ${ }^{3}$ Department of Pediatric Pneumology and Allergology, University Hospital \\ (CHU), Toulouse, France. ${ }^{4}$ Department of Pediatric Intensive Care Unit, University Hospital (CHU), Toulouse, France.}

Published: 16 December 2015

doi:10.1186/1749-8090-10-S1-A66

Cite this article as: Cuttone et al.: Surgical treatment of congenital

anomalies of the aortic arch : Long-term results. Journal of Cardiothoracic Surgery 2015 10(Suppl 1):A66. 